\title{
Contribution of Fineness Level of Fly Ash to the Compressive Strength of Geopolymer Mortar
}

\author{
Firdaus $^{1,{ }^{*}}$, Ishak Yunus $^{1}$, and Rosidawani ${ }^{2}$ \\ ${ }^{1}$ Civil Engineering Department, Faculty of Engineering, Bina Darma University, Palembang 30264, \\ Indonesia \\ ${ }^{2}$ Civil Engineering Department, Faculty of Engineering, Universitas Sriwijaya, Palembang,30136, \\ Indonesia
}

\begin{abstract}
The development of geopolymers has allowed the flash as the substitution of cement in the application of concrete. Therefore, this will be very useful considering the quite abundant by-product materials from power plants burning coal in South Sumatera. However, the untreated fly ash from the source caused its fineness level unpredictable, whereas the fineness of binder in cementitious material significantly affects the mechanical properties of the harden. Therefore, this study aims to determine the contribution of the fineness level of fly ash to the compressive strength of geopolymer mortar, as well as its excellent composition. Type F fly ash from Tanjung Enim Power Plant was treated by filtering to obtain different fineness levels based on the fall zones of the ash. Activators used in geopolymer mixing were sodium hydroxide $(\mathrm{NaOH})$ and sodium silicate $\left(\mathrm{Na}_{2} \mathrm{SiO}_{3}\right)$ with three activator/fly ash ratios which was $0.25,0.35$ and 0.45 . The results showed that the fineness level based on fall zone as well as the activator to fly ash ratio significantly influenced the compressive strength of the geopolymer mortar. The compressive strength of the F4-P4 specimen of geopolymer mortar with zone- 4 fly ash and an activator ratio of 0.45 achieved $28.2 \mathrm{MPa}$ at 28 days.
\end{abstract}

\section{Introduction}

Concrete, as the most favorite material, increases in its usage through the years and requires the availability of seemingly unlimited amounts of each composition material. Consequently, the increasing concrete usage results in high demand for cement. As known, the cement industry is one of the main contributors to $\mathrm{CO}_{2}$ emissions in the air. One ton of cement produced causes one ton of $\mathrm{CO}_{2}$ emitted into the air. Carbon dioxide emissions are causing global warming, which causes climate change. For this reason, the research for partial and full cement substitution in concrete has gained a lot of attention in the past decades.

Cementitious materials such fly ash, silica fume, slag, rice husk ash, metakaolin and others are some alternatives that have been proven to be viable as a partial substitution for cement. Fly ash as a waste material of coal combustion is the most available compared to

* Corresponding author: firdaus.dr@gmail.com 
other materials. Commonly, fly ash addition to concrete is about $10-15 \%$. However, the use of more than $50 \%$ fly ash in concrete has been developed and demonstrated good results in previous research $[1,2]$. Although the quality of the concrete did not increase significantly, it still showed excellent mechanical properties.

Utilization of $100 \%$ fly ash in substituting cement as a binder has potential in concrete production [3-5]. Fly ash, which combined with a type of activator that contains silica is engineered as an adhesive material through a chemical reaction and produces a new kind of material called a geopolymer. Davidovits [6,7] pioneered this technique and has presented promising results of geopolymer technology as an alternative for an adhesive cement matrix. Geopolymer binder is derived from natural ingredients and undergoes a polymerization reaction in the hardening process. Natural materials are preferred as a replacement for cement and should contain silica and alumina oxide [7]. The need for a high content of silica and alumina oxide are the key ingredients that undergo polymerization since it will produce a binder in the geopolymer concrete.

Furthermore, the development of geopolymer as an adhesive which can replace cement matrix is a wide open research area. Therefore, optimization of the characteristics of fly ash from different sources in its use as a natural geopolymer ingredient still requires attention. The physical and chemical properties of the final fly ash product affect the geopolymer matrix. Moreover, the type and dosage of activators used can produce a geopolymer matrix has the possibility to optimize this kind of excavated material product. So far, research results have shown that geopolymer concrete has very remarkable properties in strength and performance $[3,5,8]$.

The exploration of geopolymer concrete with a variety of features for application in building construction still has a long way to go. Characteristics of the manufacturing process, particularly the technical properties of strength and durability in aggressive environments, as well as the behavior of structural elements using geopolymer concrete are still being developed. One of the manufacturing processes is a treatment of the fly ash as the primary material of geopolymer. This research results how the treatment of the fly ash in fineness level influences the mechanical properties of the geopolymer mortar.

\section{Experimental program}

\subsection{Filtering of fly ash}

The fly ash was treated based on the fall zone parameter, which indicates the fineness of the fly ash. The fall zone parameter was modified with fly ash filtering tool, which is shown in Fig. 1.

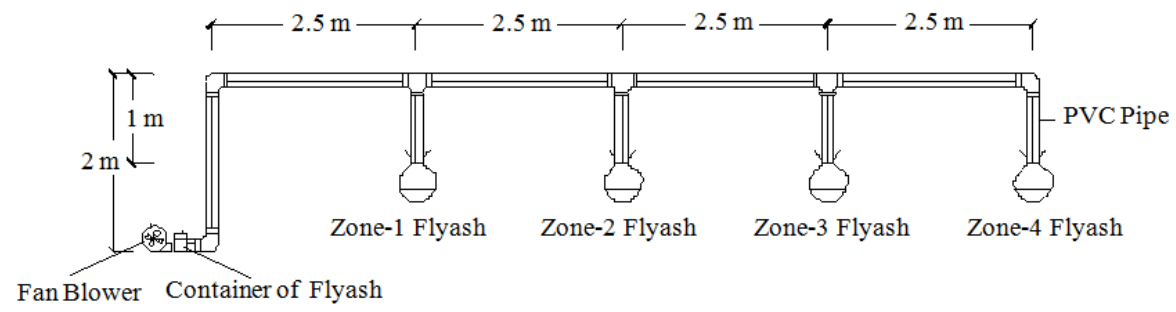

Fig. 1. Fly ash filtering based on fall zone.

The fineness of the fly ash samples was determined by four equally divided fall zones based on distance. The fell fly ash in each zone was used as an ingredient in the mixing of 
different geopolymer mortar specimens. Fly Ash employed in this work is procured from Tanjung Enim Power Plant in South Sumatera Indonesia and classified as the type F.

\subsection{Properties of fly ash}

Fly ash inspection included the examination of the result of chemical tests with the X-ray fluorescence (XRF) method to find out the chemical and mineral structures of the fly ash. Moreover, the particle size analysis (PSA) was used to determine the grain size of the fly ash, and the X-ray diffraction (XRD) testing to determine the mineral elements and relative composition of the fly ash. Table 1 gives the XRF analysis results.

Table 1. XRF analysis data of fly ash composition.

\begin{tabular}{|l|c|c|c|c|c|c|c|c|c|c|}
\hline Oxides & $\mathbf{S i O}_{2}$ & $\mathbf{F e}_{2} \mathbf{O}_{\mathbf{3}}$ & $\mathbf{C a O}$ & $\mathbf{A l}_{2} \mathbf{O}_{\mathbf{3}}$ & $\mathbf{M g O}$ & $\mathbf{S O}_{3}$ & $\mathbf{N a}_{\mathbf{2}} \mathbf{O}$ & $\mathbf{K}_{\mathbf{2}} \mathbf{O}$ & $\mathbf{T i O}_{\mathbf{2}}$ & $\mathbf{P}_{\mathbf{2}} \mathbf{O}_{\mathbf{5}}$ \\
\hline Zone 0 (\%) & 43.61 & 4.59 & 3.63 & 20.75 & 1.00 & 0.96 & 2.23 & 0.51 & 0.68 & 0.20 \\
\hline Zone 4 (\%) & 55.40 & 5.24 & 3.71 & 27.88 & 1.24 & 0.35 & 2.26 & 0.56 & 0.79 & 0.22 \\
\hline
\end{tabular}

Table 1 shows that the fineness level significantly influences the mineral composition of the fly ash. The finest filtered fly ash (zone-4), contains the higher silica and alumina. These materials are indispensable in geopolymer concrete since they are synthetic inorganic compound aluminosilicates [7].

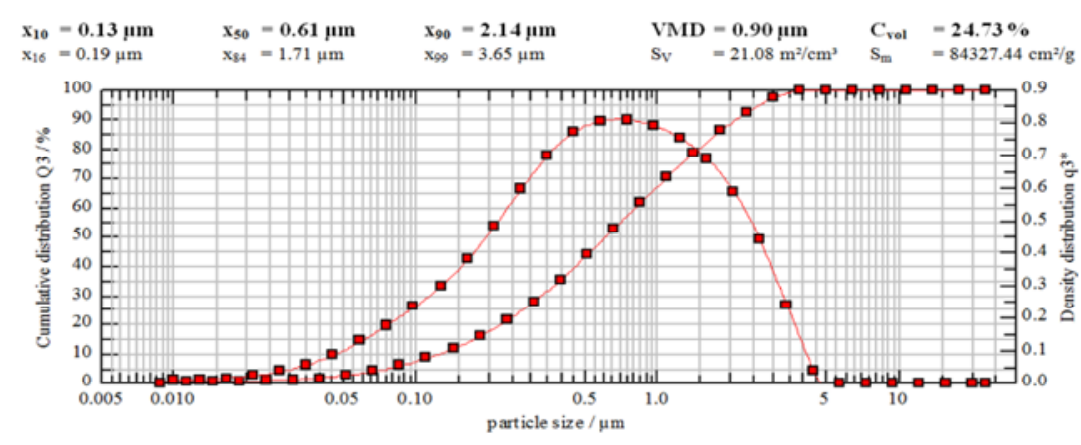

(a) Zone-0 fly ash

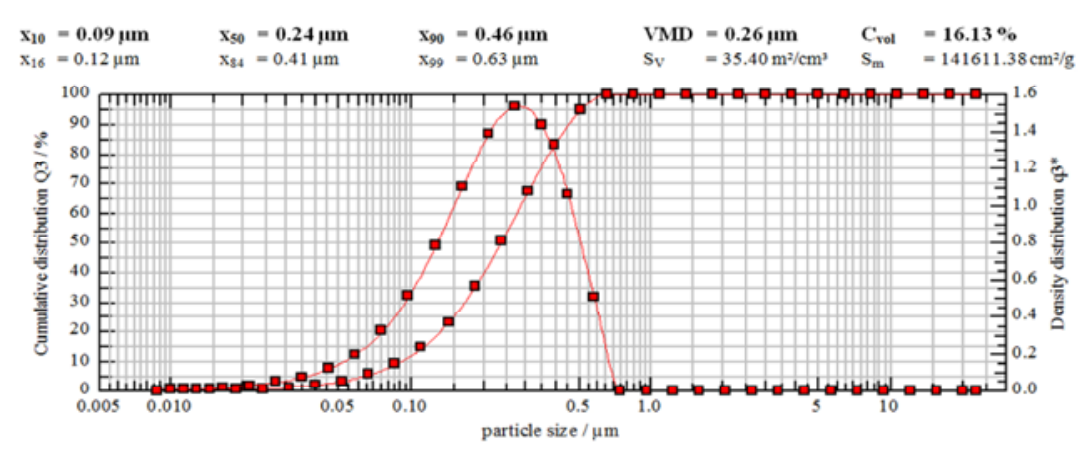

(b) Zone-1 fly ash 


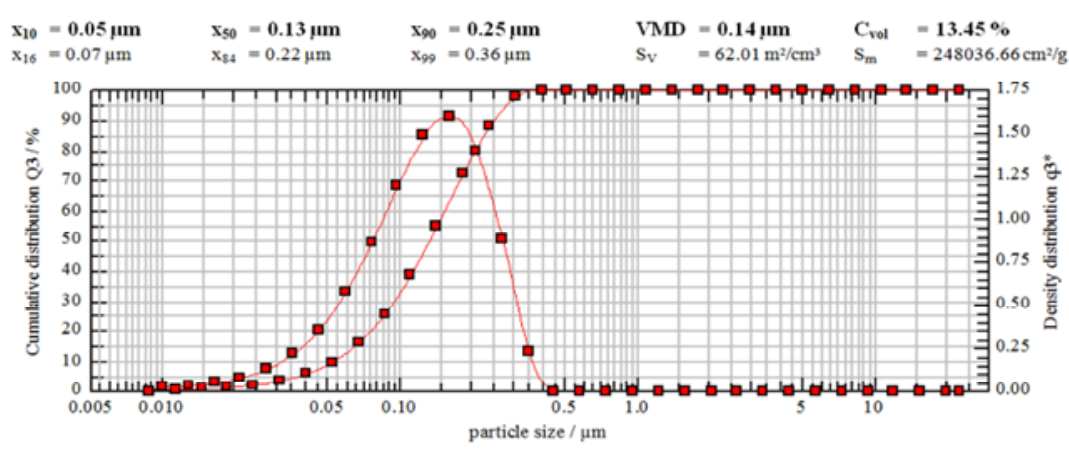

(c) Zone-2 fly ash

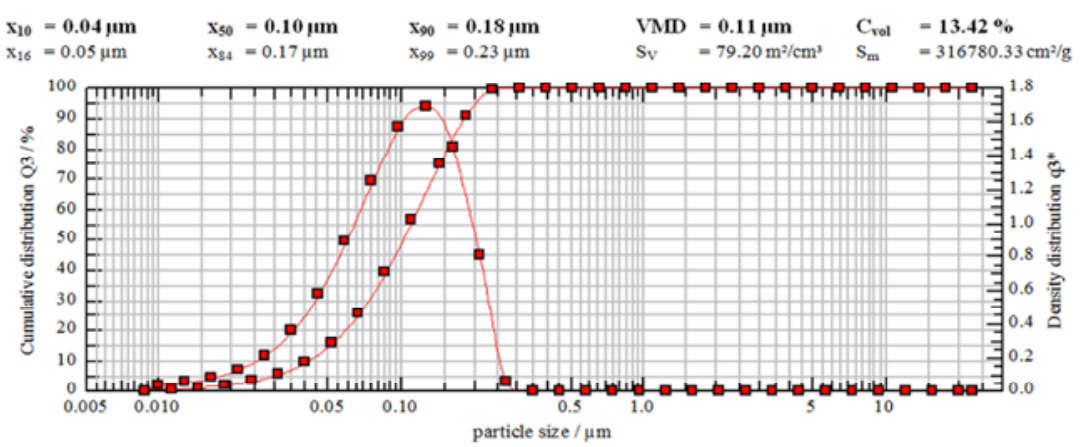

(d) Zone-3 fly ash

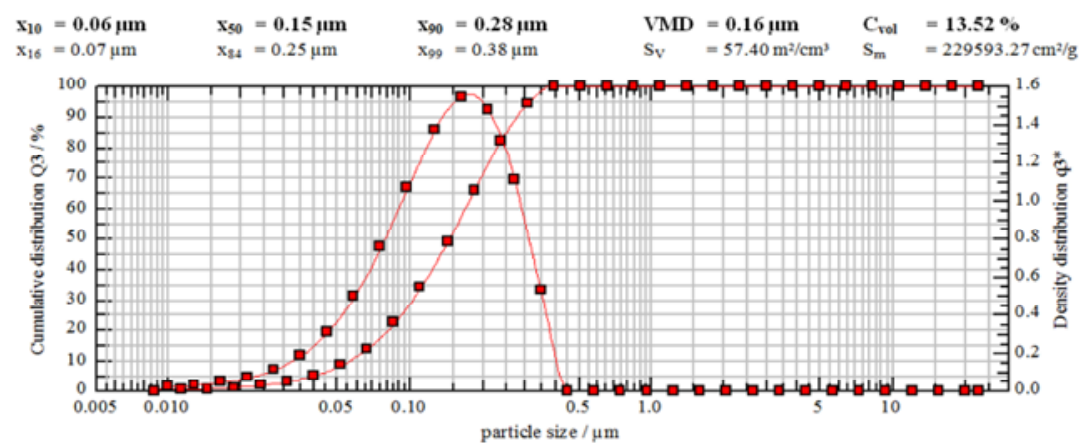

(e) Zone-4 fly ash

Fig. 2. Particle size analysis data of fly ash based on fall zones.

The results of the particle size analysis (PSA) of the fly ash specimens is drawn in Fig. 2. The grain size of unfiltered (original) zone-0 fly ash was $0.13 \mu \mathrm{m}$ for $\mathrm{X}_{10}$ and $3.65 \mu \mathrm{m}$ for $\mathrm{X}_{99}$. Meanwhile, the grain size was $0.09 \mu \mathrm{m}$ for $\mathrm{X}_{10}$ and $0.63 \mu \mathrm{m}$ for $\mathrm{X}_{99} ; 0.05 \mu \mathrm{m}$ for $\mathrm{X}_{10}$ and $0.36 \mu \mathrm{m}$ for $\mathrm{X}_{99} ; 0.04 \mu \mathrm{m}$ for $\mathrm{X}_{10}$ and $0.23 \mu \mathrm{m}$ for $\mathrm{X}_{99} ; 0.06 \mu \mathrm{m}$ for $\mathrm{X}_{10}$, and 0.38 $\mu \mathrm{m}$ for zone-1, $-2,-3$ and -4 fly ash respectively. The $\mathrm{X}_{10}$ and $\mathrm{X}_{99}$ values of the fly ash from each zone showed that the grain size was fine in the more distant zones. Therefore, this test 
show there is a significantly different fineness between untreated fly ash (Zone 0) and the most remote zone (Zone 4 ).

Fig. 3 (a-e) show the diffraction patterns from the XRD diffraction test of the fly ash. The higher mineral quartz and the finer fly ash produce the higher peak of diffraction. Besides, there was also quartz mineral hematite $\left(\mathrm{Fe}_{2} \mathrm{O}_{3}\right), \mathrm{Si}_{2}$, and $\mathrm{Al}_{6} \mathrm{Si}_{2} \mathrm{O}_{3}$.

Those figures show the diffraction patterns of the fly ash specimens for each zone (0-4). The data clearly demonstrate the difference in composition of the fly ash for each level of fineness. Although all types of the fly ash had an amorphous semi-crystalline form, they differed among other in their degree of fineness.

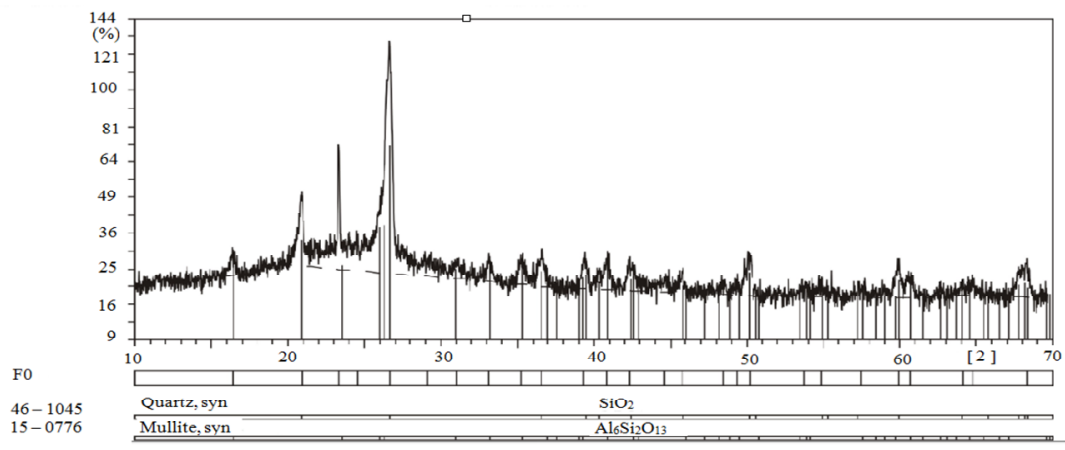

(a) Zone-0 fly ash

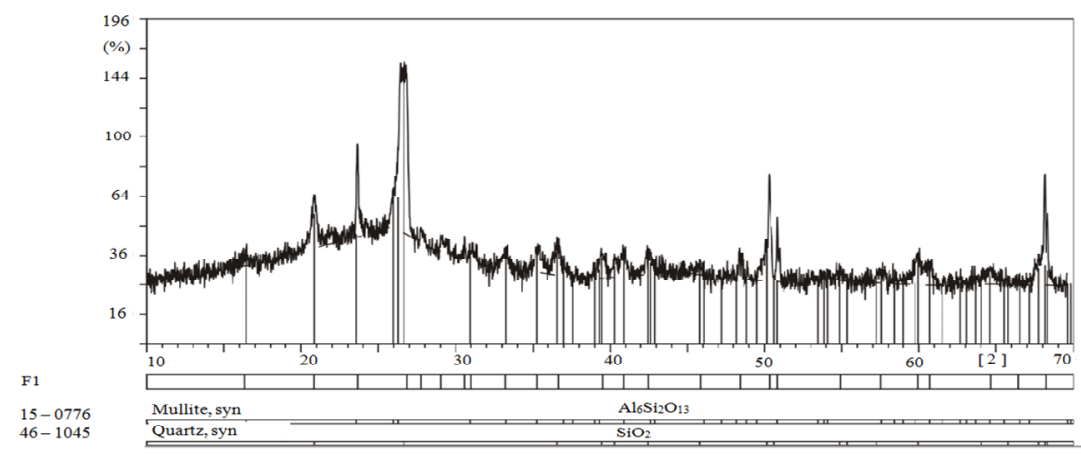

(b) Zone-1 fly ash

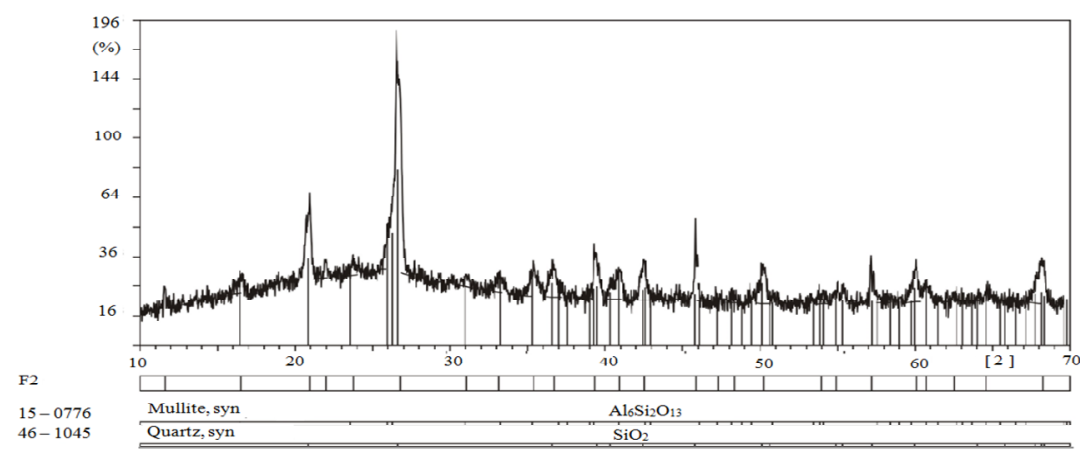

(c) Zone-2 fly ash 


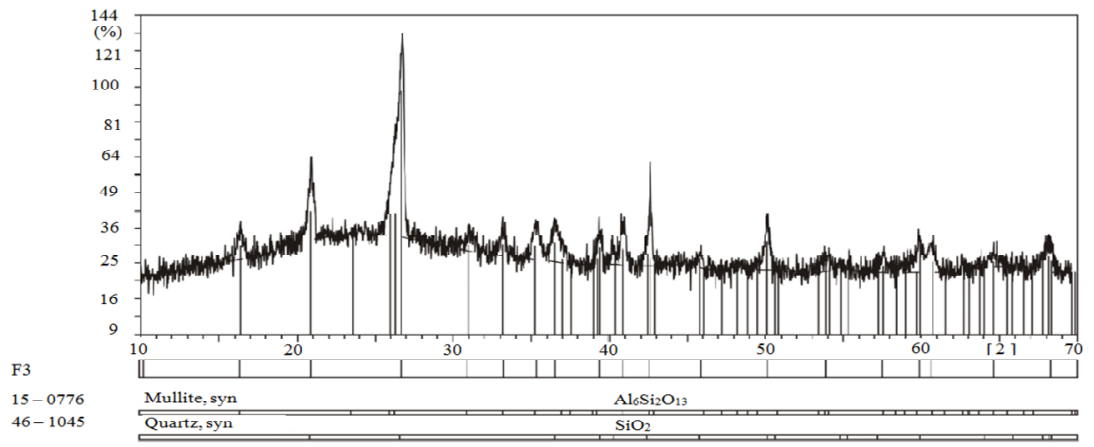

(d) Zone-3 fly ash

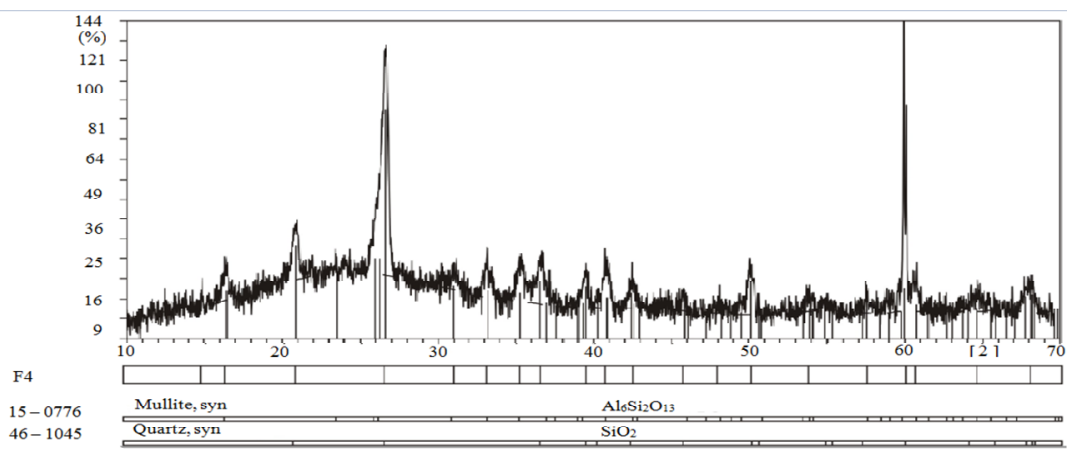

(e) Zone-4 fly ash

Fig. 3. XRD diffraction test of fly ash results based on fall zones.

\subsection{Specimens preparation}

The variables in this study consisted of five fly ash fineness levels (F0-F4), three activator/fly ash ratios (P2, P3, and P4) and three test ages (7, 21, and 28 days). All of the variables were compared according to the parameter of compressive strength.

Three mixtures of geopolymer mortar were prepared based on the optimum of trial mix design with the compositions which were differentiated by the amount of activator. Sodium hydroxide and sodium silicate were used as an alkaline activator to synthesize the geopolymer with different activator/fly ash ratios which were $0.25,0.35$ and 0.45 . Table 2 shows the mix proportion for $1 \mathrm{~m}^{3}$ mortar using water/fly ash ratio of 0.4 . The high range water reducer (HRWR) with HRWR/fly ash ratio of $0.7 \%$ was used to improve the workability.

Table 2. Composition of geopolymer mortar.

\begin{tabular}{|c|l|c|c|c|}
\hline \multirow{2}{*}{ No. } & \multicolumn{2}{|c|}{$\begin{array}{c}\text { Material } \\
(\mathbf{k g})\end{array}$} & \multicolumn{3}{c|}{ Activator ratio (\%) } \\
\cline { 3 - 5 } & & 0.25 & 0.35 & 0.45 \\
\hline 1 & Fly ash & 408 & 408 & 408 \\
\hline 2 & Sand & 652 & 652 & 652 \\
\hline 3 & Sodium silicate (water glass) & 73 & 103 & 131.3 \\
\hline 4 & Sodium hydroxide (potassium) & 28.5 & 41 & 52.1 \\
\hline 5 & Water & 163 & 163 & 163 \\
\hline 6 & Superplastizer & 2.8 & 2.8 & 2.8 \\
\hline
\end{tabular}




\section{Results and discussions}

Compressive strength tests were conducted on the geopolymer mortar with sodium silicate and sodium hydroxide as an activator at varying ratios to fly ash of $0.25 \%, 0.35 \%$ and $0.45 \%$ (P2, P3, and P4) and varying fineness of fly ash (F0, F1, F2, F3, and F4). The compressive test was executed on day 7,21 , and 28 , after curing is applied from one day after casting until one day before testing. Table 3 shows the test results of the average compressive strength of the geopolymer mortar specimens.

Table 3. Compressive strength of geopolymer mortar.

\begin{tabular}{|c|c|c|c|c|c|c|c|c|c|c|c|c|c|c|c|}
\hline \multirow{3}{*}{$\begin{array}{c}\text { Age of } \\
\text { Test } \\
\text { (day) }\end{array}$} & \multicolumn{15}{|c|}{ Compressive Strength (MPa) } \\
\hline & \multicolumn{3}{|c|}{ F0 } & \multicolumn{3}{|c|}{ F1 } & \multicolumn{3}{|c|}{$\mathrm{F} 2$} & \multicolumn{3}{|c|}{ F3 } & \multicolumn{3}{|c|}{ F4 } \\
\hline & $\mathrm{P} 2$ & P3 & $\mathrm{P} 4$ & $\mathrm{P} 2$ & P3 & P4 & $\mathrm{P} 2$ & P3 & P4 & $\mathrm{P} 2$ & P3 & P4 & $\mathrm{P} 2$ & P3 & P4 \\
\hline 7 & 1.5 & 3.7 & 4.3 & 2.7 & 4.1 & 6.2 & 3.9 & 5.0 & 8.4 & 4.8 & 5.0 & 10.7 & 9.7 & 7.8 & 14.6 \\
\hline 21 & 2.0 & 5.2 & 9.0 & 3.2 & 5.3 & 12.2 & 3.3 & 6.3 & 12.0 & 4.6 & 5.9 & 14.9 & 10.6 & 11.8 & 26.3 \\
\hline 28 & 2.6 & 5.6 & 9.5 & 3.7 & 6.2 & 15.5 & 3.6 & 6.8 & 19.2 & 4.8 & 6.9 & 17.5 & 10.8 & 12.5 & 28.2 \\
\hline
\end{tabular}

The curve of specimen F-P2 and F-P3 in Fig. 4 (a) and (b) indicates that there was a slight increase in compressive strength due to the test age. An insignificant increase of all the zone variables for each specimen was shown from the $7^{\text {th }}$ to the $28^{\text {th }}$ day. In contrary, the curve of F-P4 in Fig. 4(c) shows that the compressive strength of each specimen had increased significantly with the testing age. Each figure shows that the compressive strength of the geopolymer mortar from the most distant zone (F4) had the highest compressive strength. There was a significant increase in the compressive strength of the F4 zone compared to the original fly ash (zone 0). Fig. 5 clearly shows the increasing compressive strength on the $28^{\text {th }}$ day of each percentage of activators.

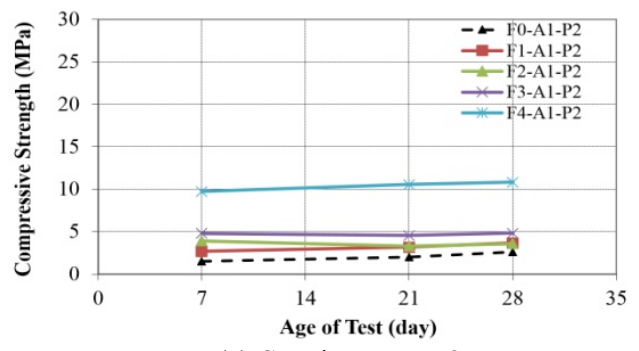

(a) Specimens F-P2

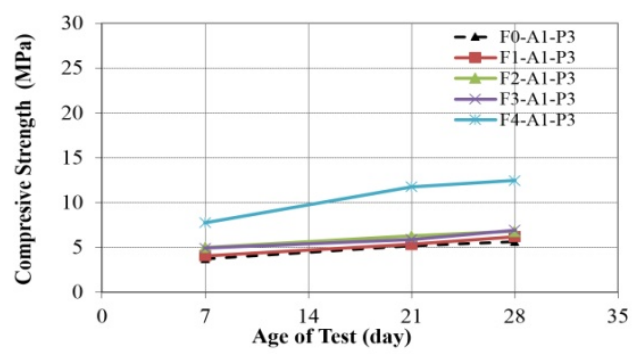

(b) Specimen F-P3

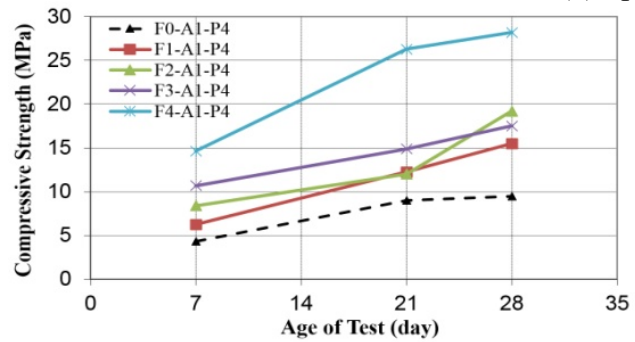

(c) Specimen F-P4

Fig. 4. Compressive strength of specimen F-P2, F-P3 and F-P4. 


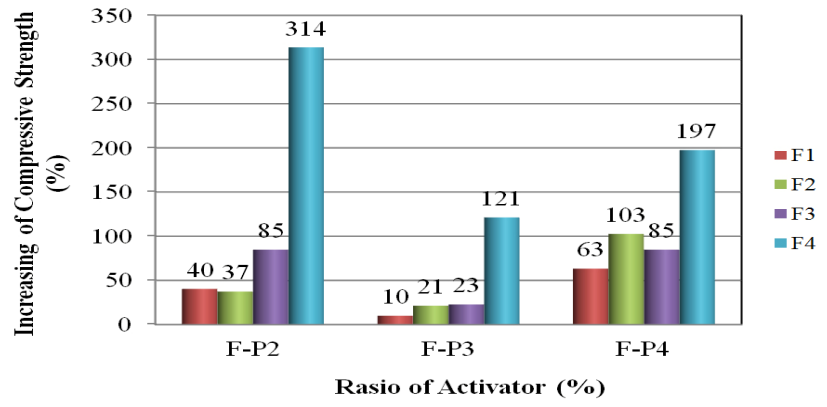

Fig. 5. The Increasing of compressive strength on the $28^{\text {th }}$ day.

From all the compressive strength results perform that the specimens with $0.45 \%$ activator (F-P4) showed the highest compressive strength. The specimens with fly ash from each fall zone with $0.45 \%$ activator (F-P4) show the significant increasing of compressive strength compared to zone- 0 . Fly ash fineness based on fall zones contributed significantly to the compressive strength of the geopolymer.

\section{Conclusions}

i) Fly ash fineness based on fall zones contributed significantly to the compressive strength of the geopolymer mortar.

ii) Geopolymer mortars using fly ash with fineness based on fall zones and mixed with water glass and potassium activators showed a significant increase in compressive strength. The increase in compressive strength of each percentage of activator compared to zone-0 was $197.47 \%, 121.28 \%$ and $313.74 \%$ for the for the F4-P4 mixture of the F-P4 specimens, for the F4-P3 mixture of the F-P3 specimens, and an F4-P2 mixture of the F-P2 specimens respectively.

iii) The maximum compressive strengths of the geopolymer mortars based on the fineness level and the composition of the mixture at 28 days were: $28.20 \mathrm{MPa}, 12.48 \mathrm{MPa}$, and 10.84 MPa for F4-P4, F4-P3 and F4-P2 respectively.

iv) The increase in compressive strength compared to fall zone- 0 was $313.74 \%$ of F4-P2, while the maximum compressive strength was $28.2 \mathrm{MPa}$ for F4-P4.

\section{References}

[1] V.M. Malhotra, Introduction: Sustainable development and concrete technology, ACI Concrete Int., 24 (7), 30-34 (2002)

[2] P.K. Mehta, High-performance, high-volume fly ash concrete for sustainable development, Proc.of the International Workshop on Sustainable Development and Concrete Technology, Beijing, China, 3-14, (2004)

[3] M.I.A. Aleem and P.D. Arumairaj, Optimum mix for geopolymer concrete, Indian J. of Science and Technology, 5 (3), 2299-2301 (2012)

[4] A.I. Laskar and R. Bhattacharjee, Rheology of flyash based geopolymer concrete, ACI Materials J., 108 (57), 535-543 (2011)

[5] B.S.K. Reddy, J. Varaprasad and K.N.K. Reddy, Strength and workability of low lime fly-ash based geopolymer concrete, Indian J. of Science and Technology, 3(12), 11881189 (2010) 
[6] J. Davidovits, Properties of geopolymer cements, Proc. of the First International Conference on Alkaline Cements and Concretes, Kiev State Technical University, Kiev, Ukraine, 131-149, (1994)

[7] J. Davidovits. Geopolymer chemistry and application, Geopolymer Institute, Saint Quentin, France (2008)

[8] D. Hardjito, B.V. Rangan, Development of flyash-based geopolymer concrete: progress and research needs, Proc.of the $2^{\text {nd }}$ Asian Concrete Federation Conference, Bali, Indonesia, 1-5, (2006) 